\title{
Nanoparticle T cell engagers for the treatment of acute myeloid leukemia
}

\author{
Kinan Alhallak ${ }^{1,2}$, Jennifer Sun ${ }^{1,2}$, Barbara Muz $^{1}$, Amanda Jeske ${ }^{1}$, Jessica Yavner ${ }^{1}$, \\ Hannah Bash ${ }^{1}$, Chaelee Park1, Berit Lubben ${ }^{1}$, Ola Adebayo ${ }^{1}$, Samuel Achilefu ${ }^{2,3}$, \\ John F. DiPersio ${ }^{4}$ and Abdel Kareem Azab ${ }^{1,2}$ \\ ${ }^{1}$ Department of Radiation Oncology, Washington University School of Medicine, St. Louis, MO 63110, USA \\ ${ }^{2}$ Department of Biomedical Engineering, Washington University McKelvey School of Engineering, St. Louis, MO 63130, USA \\ ${ }^{3}$ Department of Radiology, Washington University School of Medicine, St. Louis, MO 63110, USA \\ ${ }^{4}$ Department of Medicine, Washington University School of Medicine, St. Louis, MO 63110, USA
}

Correspondence to: Abdel Kareem Azab, email: kareem.azab@wustl.edu

Keywords: acute myeloid leukemia; T cell engagers; nanoparticles; 3D tissue culture model

Received: July 26, $2021 \quad$ Accepted: August 13, $2021 \quad$ Published: September 14, 2021

Copyright: @ 2021 Alhallak et al. This is an open access article distributed under the terms of the Creative Commons Attribution License (CC BY 3.0), which permits unrestricted use, distribution, and reproduction in any medium, provided the original author and source are credited.

\section{ABSTRACT}

Acute myeloid leukemia (AML) is the most common type of leukemia and has a 5 -year survival rate of $\mathbf{2 5 \%}$. The standard-of-care for AML has not changed in the past few decades. Promising immunotherapy options are being developed for the treatment of AML; yet, these regimens require highly laborious and sophisticated techniques. We create nanoTCEs using liposomes conjugated to monoclonal antibodies to enable specific binding. We also recreate the bone marrow niche using our 3D culture system and use immunocompromised mice to enable use of human AML and $T$ cells with nanoTCEs. We show that CD33 is ubiquitously present on AML cells. The CD33 nanoTCEs bind preferentially to AML cells compared to Isotype. We show that nanoTCEs effectively activate $T$ cells and induce AML killing in vitro and in vivo. Our findings suggest that our nanoTCE technology is a novel and promising immunotherapy for the treatment of AML and provides a basis for supplemental investigations for the validation of using nanoTCEs in larger animals and patients.

\section{INTRODUCTION}

Acute myeloid leukemia (AML) is the most common type of leukemia; it is characterized by the overproduction of immature myeloid stem cells in the bone marrow and has a 5-year survival rate of around $25 \%[1,2]$. The survival curves for AML patients have remained stagnant in the past decades due to the lack of newly approved therapies for AML. However, recent development in novel therapeutics and technologies have shown promising results in preclinical and clinical settings [3-5].

Exciting immunotherapy technologies that are being investigated for AML include chimeric antigen receptor $\mathrm{T}$ (CAR-T) cells and bispecific $\mathrm{T}$ cell engagers (TCEs). CAR-T cells are autologous $T$ cells that have been virally transfected to express an engineered CAR construct, containing a synthesized fragment that targets the desired surface antigen on the target cell [6]. However, the main disadvantages of this technology relative to traditional therapies include toxicity, the long-term safety profile of the viral vector, the need for frequent quality control testing throughout production, the high costs due to the need of extensive labor and expensive facility, complex production, and the inability to target multiple tumor antigens with one CAR-T cell $[7,8]$.

In addition to CAR-T cells, T cell-based therapy can be pursued with TCEs. TCE consists of two single chain variable fragments which are connected by a protein linker. One of the domains recognizes a tumor-associated surface antigen, while the other recognizes the $\mathrm{T}$ cell CD3 receptor [9]. This enables the TCE to redirect the $\mathrm{T}$ cell to the tumor and induce subsequent activation and expansion of the $T$ cell. TCEs stimulate endogenous $T$ cells and demonstrate high potency and efficacy against tumor cells [10-12], circumventing certain limitations 
of genetically engineering extracted patient $\mathrm{T}$ cells to express CARs. This immunotherapeutic option has been shown to be successful for both solid and liquid tumors, but is mostly known for the treatment of hematological malignancies [13]. The disadvantages of TCEs, however, include toxicity, expensive costs for labor and production, complex production, poor pharmacokinetics profile $\left(\mathrm{t}_{1 / 2} \sim\right.$ 2 hours), and the inability to target multiple cancer surface markers $[10,14,15]$.

We have previously developed a nanoparticle-based $\mathrm{T}$ cell engagers (nanoTCEs) technology that is based on conjugation of two monoclonal antibodies (mAbs) to the surface of a liposomal nanoparticle; one antibody is against a cancer antigen and the other is against the CD3 receptor on T cells [16]. NanoTCEs utilize existing mAbs which we conjugate to the surface of a nanoparticle, therefore taking advantage of the high specificity of existing mAbbased therapies, to engage and direct robust responses from the immune system ( $\mathrm{T}$ cells). NanoTCEs have been shown to have clear advantages compared to both CAR-T cells and TCEs; nanoTCEs are: 1) simple to produce the production of nanoparticles and chemical conjugation of readily available mAbs takes only a few hours; 2) prolonged pharmacokinetic profile ( $\mathrm{t}_{1 / 2} \sim 60$ hours), 3) modular platform allowing customizable targeting of multiple tumor and immune cell antigens [16]. Moreover, nanoTCEs has demonstrated therapeutic efficacy in endogenous $\mathrm{T}$ cell activation as well as $\mathrm{T}$ cell-directed cancer cell lysis, both in vitro and in vivo. Therefore, the nanoTCE technology represents a facile platform for development of T-cell engagement immunotherapy using any existing anti-cancer $\mathrm{mAbs}$.

There is a long-standing interest in CD33-targeted therapies AML. CD33 is a myeloid-associated marker found mainly on cells committed to the myeloid lineage and its expression is absent on non-hematopoietic cells

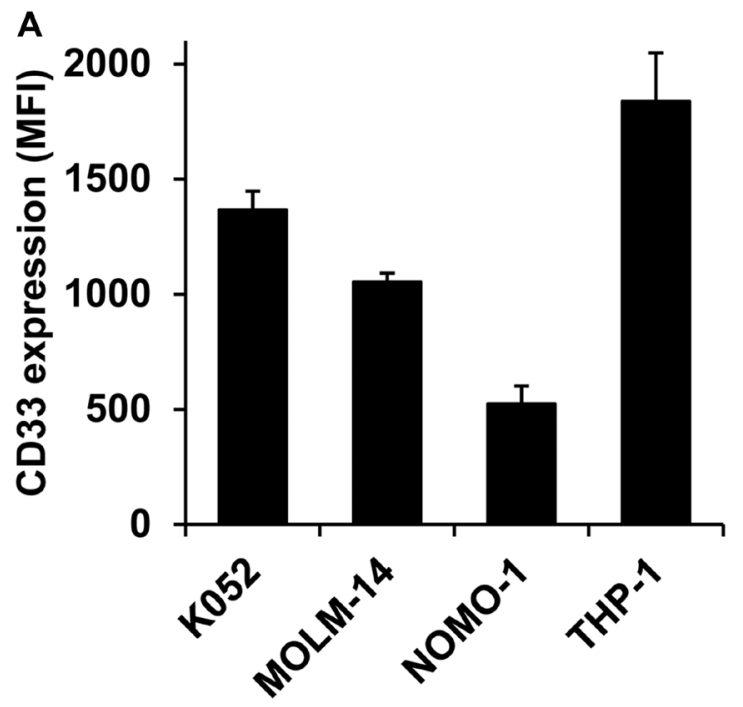

[17]. High CD33 expression has been reported on AML blasts; data show as much as $85-90 \%$ of blasts express CD33 in AML patients [18, 19]. Moreover, CD33 expression positively correlates with stage of the disease [2]. Several therapy options using CD33 as a target have been under development pre-clinically and clinically. The CD33-directed antibody-drug conjugate, gemtuzumab ozogamicin is FDA approved for AML [20]. Studies on CD33-targeted TCEs for treatment of AML have also demonstrated efficacy potential. CD33 x CD3 bi-specific TCE, AMG 330, is currently in Phase I clinical trial for relapsed/refractory as well as minimal residual disease positive AML (NCT02520427) [21-23]. Additionally, CD33 x CD3 tandom diabody, AMV564, is under Phase I clinical trial for relapsed/refractory AML (NCT03144245) [24, 25]. CD33-targeted CAR-T cells have also been explored and proven effective [26, 27]; CD33-CART cells are being explored in multiple clinical trials for children and adults with relapsed/refractory AML (NCT03971799, NCT03927261). Thus, a plethora of evidence validates CD33 as a targetable biomarker for immunotherapy in AML.

In this study, we sought to create a nanoTCE targeted to CD33 for the treatment of AML, as a versatile T-cell engagement platform.

\section{RESULTS}

CD33 is a valuable target for the treatment of AML, therefore, we first validated the presence of the marker in our experimental setup. We measured the fluorescent intensity and percent of CD33 in four different human AML cell lines. For all cell lines, CD33 was expressed in high levels (Figure 1A) and uniformly on $90-100 \%$ of the cells (Figure 1B), indicating that CD33 is a promising surface marker for nanoTCE targeting.

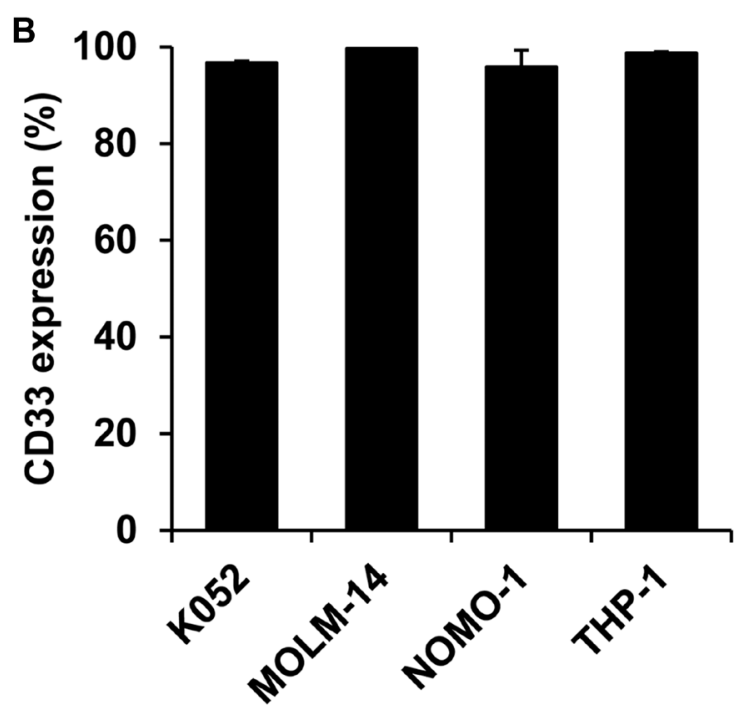

Figure 1: CD33 expression on AML cell lines. (A) Mean fluorescent intensity and (B) percent expression on K052, MOLM-14, NOMO-1, and THP-1. Data is represented as mean \pm standard deviation. 
Next, we developed AML-targeting CD33/ CD3 nanoTCEs and prepared Isotype/CD3 nanoTCEs as control. A schematic of the liposomal CD33/CD3 nanoTCE production process is shown in Figure 2A. We characterized the physicochemical properties of these nanoTCEs, including diameter, polydispersity index (PDI), and zeta potential which are shown in Table 1. We found that the properties are in accord with our previous report [16], in which the size of the nanoTCEs was about $140 \mathrm{~nm}$, with low PDI indicating the uniformity of the particle size, and with close to neutral net charge.

We then tested the binding of CD33/CD3 nanoTCEs to $\mathrm{T}$ cells and AML cell lines compared to Isotype controls. The CD33/CD3 nanoTCEs bound to T cells at 2-fold higher than Isotype (Figure 2B), and bound to AML cell lines around 2- to 3-fold higher compared to Isotype (Figure 2C).

To demonstrate the therapeutic efficacy of nanoTCEs in vitro, we investigated the effect of nanoTCEs on activation of $\mathrm{T}$ cells as well as $\mathrm{T}$ cell-mediated killing of AML cell lines in our 3DTEBM culture model [28]. 3DTEBM is a patient-derived 3D cell culture system that mimics the leukemic bone marrow niche, in which it recapitulates the tumor microenvironment and drug resistance superior than classic 2D cultures [29]. Activation of T cells was observed as increase in CD69 upregulation in CD4 (Figure 3A) and CD8 T cells (Figure 3B) following co-culture of T cells with AML cell lines with CD33/CD3 nanoTCEs, but not with Isotype/CD3 TCEs. We have shown previously that the nanoTCE is not able to activate T cells alone; this is shown by the use of the Isotype/CD3. T cells do not activate following the binding of the nanoTCE alone; it only works following the engagement of the $\mathrm{T}$ cell and the target cell via nanoTCE which aligns with the kinetic segregation model for $\mathrm{T}$ cell receptor triggering $[16$, 30]. Consequently, no T cell-mediated killing of AML cells was observed following treatment with Isotype/CD3 TCEs, while $50-75 \%$ killing was observed following treatment with CD33/CD3 nanoTCEs for 4 days (Figure 3C).

To demonstrate the therapeutic efficacy of nanoTCEs in vivo, we injected human AML THP-1 cells genetically engineered to express luciferase in an NCG immunocompromised mice model. At Day 7 of tumor inoculation, we injected human primary $\mathrm{T}$ cells to the mice and treated with nanoTCEs weekly thereafter. Mice treated with $\mathrm{CD} 33 / \mathrm{CD} 3$ nanoTCEs had significantly lower tumor burden at all time points compared with Isotype/CD3 nanoTCEs (excluding Day 6) (Figure 4A). Additionally, $100 \%$ of the $\mathrm{CD} 33 / \mathrm{CD} 3$ cohort was alive at the end of the study, while only $40 \%$ of Isotype/CD3 cohort survived past Day 62 and none past Day 66 (Figure 4B).



B

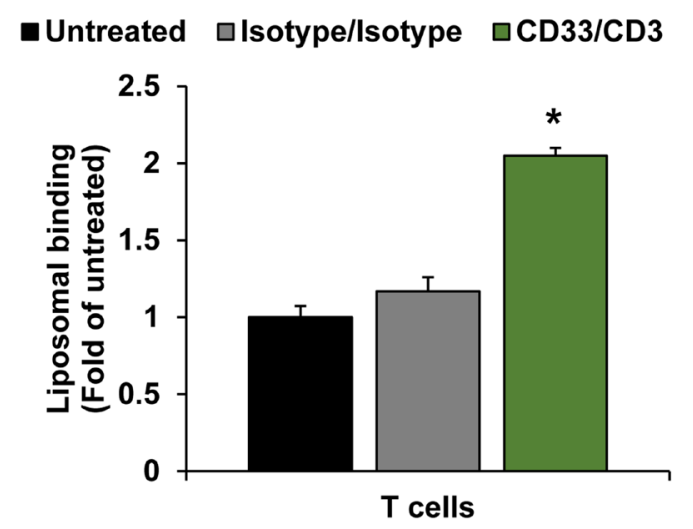

C

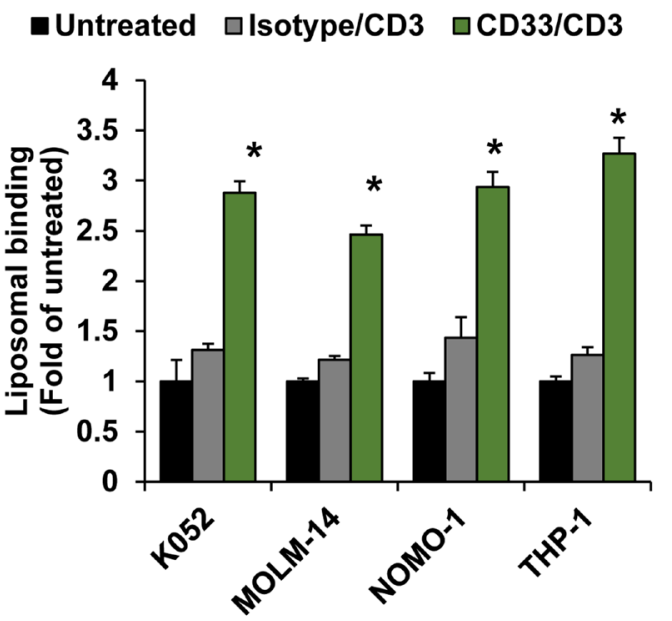

Figure 2: Development of nanoTCEs for AML. (A) Schematic of CD33/CD3 nanoTCEs production process. (B) Liposomal binding of Isotype and CD33/CD3 nanoTCEs to T cells. (C) Liposomal binding of Isotype and CD33/CD3 nanoTCEs to AML cell lines. Statistical significance between CD33/CD3 and Isotype is indicated by ${ }^{*}(p<0.05)$. Data is represented as mean \pm standard deviation. 


\section{DISCUSSION}

AML is associated with low survival rates and novel therapeutics are direly in need. In this study, we validated that CD33 is an abundant and relevant marker on AML cells, and demonstrated that our CD33/CD3 nanoTCE technology can induce T-cell directed cytotoxic activity against AML. The CD33/CD3 nanoTCEs bound preferentially to AML and T cells; this enables specific binding to only these cells and prevents binding to other hematopoietic cells to reduce off-target toxicities. T cell activation and T cell-mediated AML cell lysis was induced following the use of the nanoTCEs in vitro and in vivo.
Our nanoTCE platform uses nanoparticles to create a relatively simple to produce, reproducible, and off-the-shelf solution to overcome the major limitations associated with current immunotherapy techniques such as TCEs and CAR-T cells. Importantly, this technology is highly customizable and provides the flexibility to engage any immune cell for the treatment of the cancer of interest. In this study, we report a CD33/CD3 nanoTCE that targets the CD33 antigen with high specificity using mAbs, which enables a potent and efficacious immunotherapy treatment against AML. Future studies are warranted to investigate this therapy in combination with chemotherapy, the extent this technology eliminates
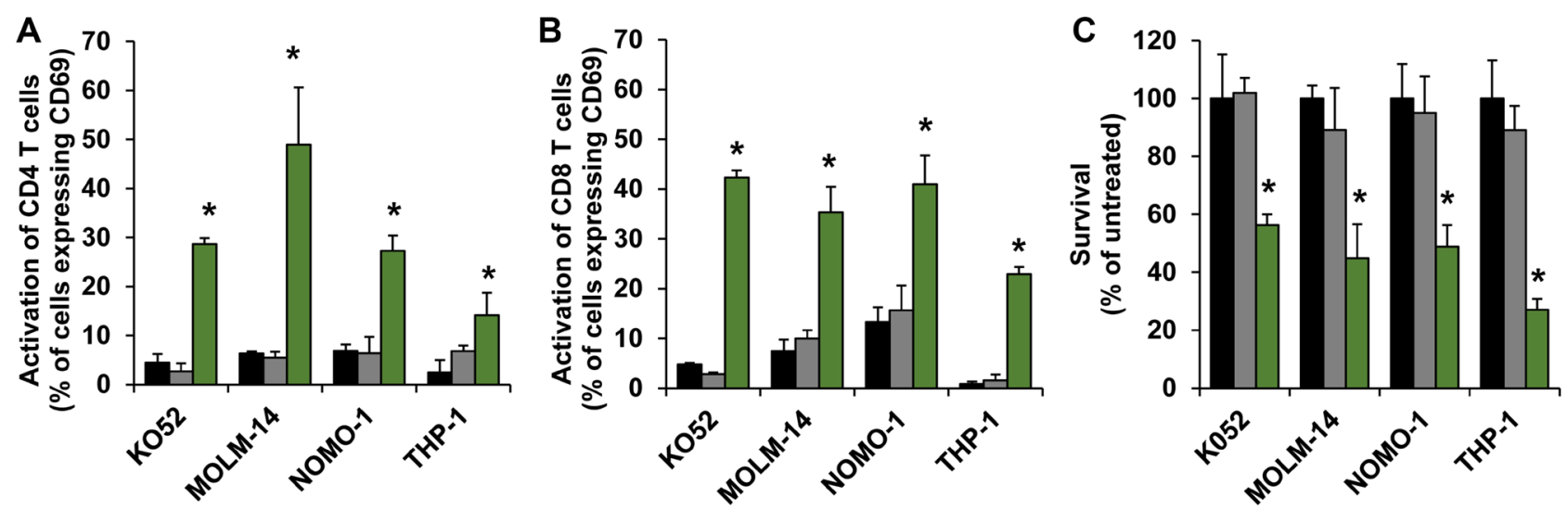

-Untreated $\square$ lsotype/CD3 $\square$ CD33/CD3

Figure 3: Efficacy of nanoTCEs in vitro. The effect of Isotype/CD3 and CD33/CD3 nanoTCEs treatment on activation of (A) CD4 and (B) CD8 T cells, and on (C) survival of AML cell lines, in 3DTEBM after 4 days. Statistical significance between CD33/CD3 and Isotype is indicated by ${ }^{*}(p<0.05)$. Data is represented as mean \pm standard deviation.
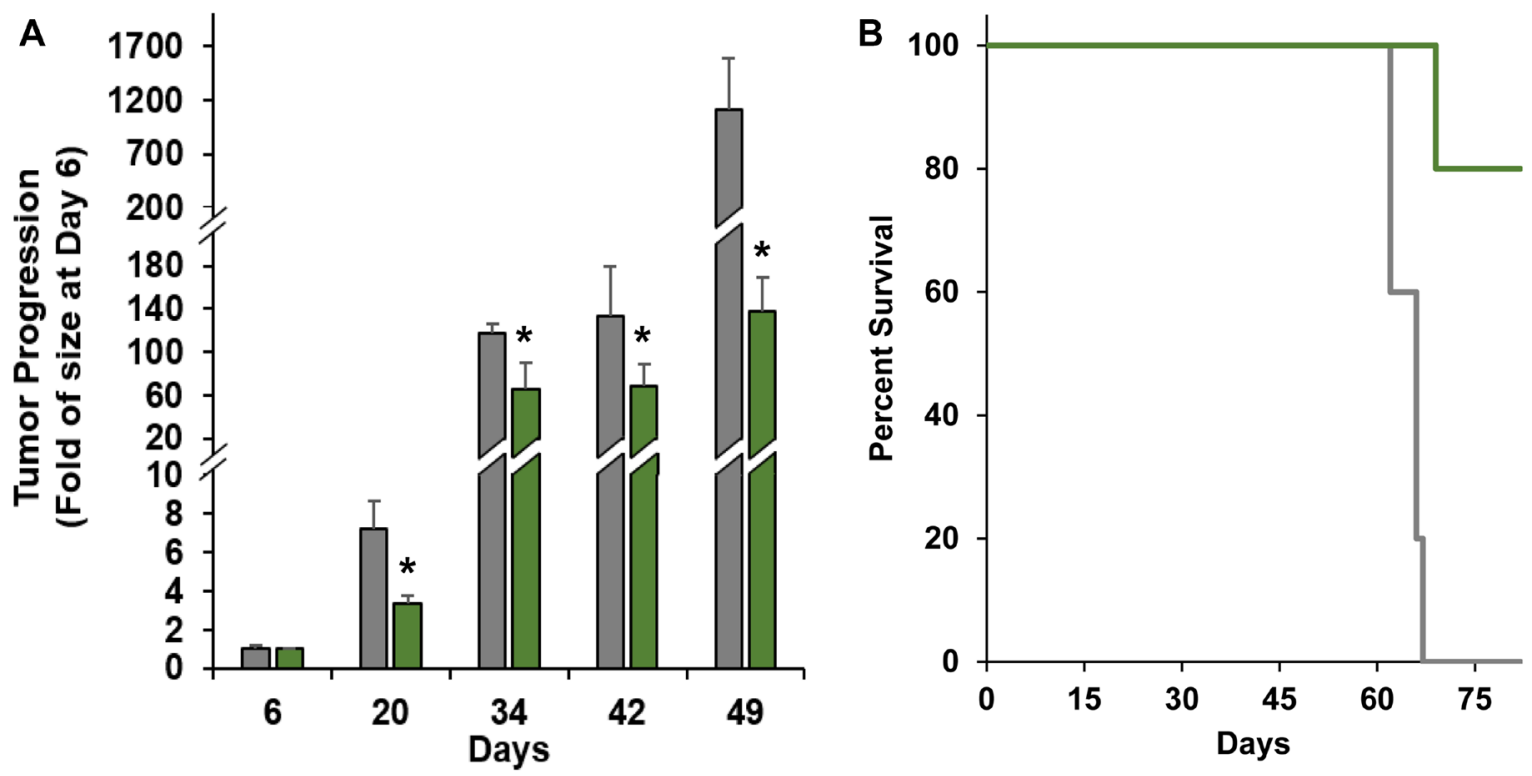

Figure 4: Efficacy of nanoTCEs in vivo. (A) Tumor progression and (B) Kaplan-Meier survival comparison between mice treated with Isotype/CD3 (grey; $n=5$ ) or CD33/CD3 nanoTCEs (green; $n=5$ ). Statistical significance between CD33/CD3 and Isotype is indicated by ${ }^{*}(p<0.05)$. Tumor progression data is represented as mean \pm standard deviation for tumor progression. 
Table 1: Characterization of nanoTCEs ${ }^{1}$

\begin{tabular}{lccc}
\hline Formulation & Diameter $(\mathbf{n m})$ & PDI $^{2}$ & Zeta Potential $(\mathbf{m V})$ \\
\hline Isotype/CD3 & $140.5 \pm 1.0$ & $0.11 \pm 0.02$ & $0.9 \pm 0.2$ \\
CD33/CD3 & $141.3 \pm 1.0$ & $0.07 \pm 0.01$ & $1.1 \pm 0.1$ \\
\hline
\end{tabular}

${ }^{1}$ Mean \pm standard deviation; ${ }^{2}$ polydispersity index (PDI).

minimal residual disease and relapse, as well as its efficacy in AML patients.

\section{MATERIALS AND METHODS}

\section{Materials and reagents}

Antibodies and Pan T Cell Isolation Kits were purchased from Miltenyi Biotec (Bergisch Gladbach, Germany). RPMI-1640, 0.25\% trypsin, L-glutamine, and penicillin-streptomycin were purchased from Corning (Corning, NY). Fetal bovine serum, lipophilic tracers, collagenase, and counting beads were purchased from Life Technologies (Carlsbad, CA). 1,2-dipalmitoyl-snglycero-3-phosphocholine (DPPC), 1,2-distearoyl-snglycero-3-phosphoethanolamine-N- [amino(polyethylene glycol)-2000] (DSPE-PEG2000), and extrusion membranes were purchased from Avanti Polar Lipids (Alabaster, AL). Cholesterol was purchased from Millipore Sigma (Burlington, MA). Streptavidin conjugation kit was purchased from Abcam (Cambridge, United Kingdom). Lipophilic tracer $\mathrm{DiO}$ was purchased from Invitrogen (Eugene, OR).

\section{Cell culture and 3DTEBM}

K052, MOLM-14, NOMO-1, and THP-1 cell lines were all obtained from the lab of John DiPersio. Peripheral blood mononuclear cells (PBMCs) were isolated from healthy donors using Ficoll-Paque PREMIUM (Millipore Sigma), and $\mathrm{T}$ cells were separated using a Pan $\mathrm{T}$ cell isolation kit. Cell lines were cultured in RPMI-1640 supplemented with $10 \%$ fetal bovine serum, $2 \mathrm{mM}$ of L-glutamine, and $1 \%$ penicillin-streptomycin. All cell cultures were cultured in NuAire water jacket incubators (NuAire, Plymouth, $\mathrm{MN}$ ) at $37^{\circ} \mathrm{C}$ and in $5 \% \mathrm{CO}_{2}$.

3D tissue engineered bone marrow (3DTEBM) cultures were established in 96-well plates by crosslinking fibrinogen in patient bone marrow supernatant at a concentration of 1 and $4 \mathrm{mg} / \mathrm{mL}$ calcium chloride and tranexamic acid [28]. The 3DTEBM was supplemented with media on top after gelling. At time of analysis, cells were retrieved by digesting 3D scaffolds with collagenase (Gibco, Life Technologies) for $2 \mathrm{~h}$ at $37^{\circ} \mathrm{C}$.

\section{Preparation and characterization of nanoTCEs}

The procedure of making nanoTCEs has been previously described [16]. Briefly, nanoTCEs were prepared with three components: cholesterol, DPPC, and DSPE-PEG2000 with a molar ratio equivalent to 30 : 65: 5. Lipids were mixed and solubilized in chloroform, and evaporated through a rotary evaporator (Heidolph, Schwabach, Germany) to form a thin lipid film. The film was then hydrated, and the resulting suspension was extruded using the Avestin LiposoFast LF-50 (Ottawa, ON, Canada) with $100 \mathrm{~nm}$ polycarbonate membranes [31, 32]. The biotinylated antibodies (Isotype, CD3, and/or CD33) were conjugated to the liposomes using streptavidin and biotin reaction [33]. Malvern Zetasizer Nano ZS90 (Malvern, Worcestershire, United Kingdom) was used to determine zeta potential, diameter, and polydispersity index. Fluorescent liposomes were prepared by dissolving $\mathrm{DiO}$ in the lipid/chloroform mixture before film formation.

\section{Protein expression}

Cells were stained with anti-CD33 APC antibody in $4^{\circ} \mathrm{C}$ for one hour, washed, and analyzed by flow cytometry using MACSQuant Analyzer 10 (Miltenyi Biotec) with an Ex/Em of $635 / 655-730 \mathrm{~nm}$. Cells were gated using forward and side scatter and analyzed for relative mean fluorescent intensity (MFI) of APC using BD FlowJo Software $[34,35]$.

\section{Liposomal binding}

Each nanoTCE were prepared with a lipophilic fluorescent tracer $\mathrm{DiO}$. Cell lines and $\mathrm{T}$ cells were treated with Isotype/Isotype or CD33/CD3 nanoTCEs $(3.7 \mathrm{nM})$ for two hours at $37^{\circ} \mathrm{C}$. Cells were spun down, washed, and analyzed by flow cytometry with Ex/Em of 488/525 $\pm 25 \mathrm{~nm}$. Cells were gated using forward and side scatter and analyzed for MFI of DiO using BD FlowJo Software.

\section{Activation of $T$ cells and $T$ cell-mediated killing of AML in vitro}

Cell lines were cultured with healthy donor $\mathrm{T}$ cells in the 3DTEBM and treated with Isotype/CD3 or CD33/CD3 nanoTCEs at a concentration of $3.7 \mathrm{nM}$ for 4 days. Cultures were digested, and cells were retrieved and stained with anti-CD3 PE, anti-CD4 FITC, anti-CD8 Violet, and anti-CD69 APC antibodies for one hour at $4^{\circ} \mathrm{C}$. Samples were analyzed by flow cytometer with Ex/Em of $488 / 585 \pm 20,488 / 525 \pm 25,405 / 450 \pm 25$, and 635/655$730 \mathrm{~nm}$, respectively. Cells were gated using forward and side scatter followed by double positive $\mathrm{CD} 3+/ \mathrm{CD} 4+$ or 
CD3+/CD8+, both of which were analyzed for $\%$ of cells positive for CD69 using BD FlowJo Software.

\section{T cell-mediated Killing of AML in vitro}

Cell lines (pre-labeled with $\mathrm{DiO}$ ) were incubated with healthy donor $\mathrm{T}$ cells in the 3DTEBM and treated with Isotype/CD3 or CD33/CD3 nanoTCEs at a concentration of $3.7 \mathrm{nM}$ for 4 days. Counting beads were added to the culture before matrix digestion. The cells were retrieved and analyzed by flow cytometry. Number of AML cells were analyzed as $\mathrm{DiO}+$ cells and normalized to the number of counting beads using BD FlowJo Software.

\section{T cell-mediated Killing of AML in vivo}

Immunodeficient NCG mice (strain: 572), female, 50-56 days old, were purchased from Charles River (Wilmington, MA), and all experiments using these rodents were in compliance with the Institutional Animal Care and Use Committee at Washington University. Human AML cell line, THP-1 CBR cells $\left(1 \times 10^{6} /\right.$ mouse) were injected intravenously (i.v.) into 10 NCG mice. One week after tumor inoculation, human $\mathrm{T}$ cells $\left(5 \times 10^{6} / \mathrm{mouse}\right)$ were injected i.v. Mice were randomized into two groups $(n=5)$ and were treated i.v. with Isotype/CD3 or CD33/CD3 nanoTCEs $(0.5$ $\mathrm{mg} / \mathrm{mouse}$ ) weekly for a total of four weeks. Tumor progression was tracked by weekly bioluminescent imaging. Mice were injected with D-luciferin $(150 \mu \mathrm{g} /$ $\mathrm{kg}$ ) intraperitoneally, and tumor burden was detected using an IVIS 50 bioluminescence imaging system (PerkinElmer, Waltham, MA, USA) 10 minutes postluciferin injection, and images were analyzed using Living Image 2.6 software (PerkinElmer). Mice were monitored on a daily basis to record survival.

\section{Statistical analyses}

All experiments were independently replicated three times and performed in quadruplicates, and animal experiments consisted of five mice per group; data from in vitro and in vivo experiments were expressed as means \pm standard deviation. Statistical significance was analyzed using a Student's $t$-test, one-way, or two-way analysis of variance. Log-rank test was used to compare the Kaplan Meier curves. $P$-values less than 0.05 were used to indicate statistically significant differences.

\section{Abbreviations}

AML: Acute myeloid leukemia; CAR-T cells: chimeric antigen receptor T cells; TCEs: bispecific T cell engagers; nanoTCEs: Nanoparticle T cell engagers; mAbs: monoclonal antibodies; 3DTEBM: 3D tissue engineered bone marrow.

\section{Author contributions}

KA designed and conducted the experiments, analyzed the data, and wrote the manuscript. JS conducted experiments, analyzed the data, and wrote the manuscript. $\mathrm{BM}, \mathrm{JY}, \mathrm{HB}, \mathrm{CP}, \mathrm{BL}$, and OA conducted experiments and analyzed data. SA and JFD designed experiments. AKA conceived the idea, designed experiments, analyzed the data, and wrote the manuscript. All authors have read and agreed to the published version of the manuscript.

\section{CONFLICTS OF INTEREST}

AKA and KA have filed a patent with regards to the $T$ cell engagers described in this study. AKA is the founder and owner of Cellatrix LLC and Targeted Therapeutics LLC. Some of the experiments were performed using 3DTEBM products supplied by Cellatrix LLC; however, both companies had no role in the study. Other authors state no conflicts of interest.

\section{FUNDING}

This study was supported by the National Institutes of Health (NIH) grants: U54CA199092, P50CA094056, and P30CA091842, and by the Paula C. and Rodger O. Riney Blood Cancer Research Initiative Fund. KA was funded by an award from the National Center for Advancing Translational Sciences of the NIH (TL1TR002344).

\section{REFERENCES}

1. Siegel RL, Miller KD, Jemal A. Cancer statistics, 2016. CA Cancer J Clin. 2016; 66:7-30. https://doi.org/10.3322/ caac. 21332. [PubMed]

2. Pelcovits A, Niroula R. Acute Myeloid Leukemia: A Review. R I Med J (2013). 2020; 103:38-40. [PubMed]

3. Guy DG, Uy GL. Bispecific Antibodies for the Treatment of Acute Myeloid Leukemia. Curr Hematol Malig Rep. 2018; 13:417-25. https://doi.org/10.1007/s11899-018-0472-8. [PubMed]

4. Tabata R, Chi S, Yuda J, Minami Y. Emerging Immunotherapy for Acute Myeloid Leukemia. Int J Mol Sci. 2021; 22:1944. https://doi.org/10.3390/ijms22041944. [PubMed]

5. Alhallak K, Sun J, Muz B, Azab AK. 18 - Biomaterials for cancer immunotherapy. Editor(s): Kinam Park, In Woodhead Publishing Series in Biomaterials, Biomaterials for Cancer Therapeutics (Second Edition), Woodhead Publishing. 2020. pp 499-526. https://doi.org/10.1016/ B978-0-08-102983-1.00018-1.

6. Stanchina M, Soong D, Zheng-Lin B, Watts JM, Taylor J. Advances in Acute Myeloid Leukemia: Recently Approved 
Therapies and Drugs in Development. Cancers (Basel). 2020; 12:3225. https://doi.org/10.3390/cancers12113225. [PubMed]

7. Bedoya F, Frigault MJ, Maus MV. The Flipside of the Power of Engineered T Cells: Observed and Potential Toxicities of Genetically Modified T Cells as Therapy. Mol Ther. 2017; 25:314-20. https://doi.org/10.1016/j.ymthe.2016.11.011. [PubMed]

8. Levine BL, Miskin J, Wonnacott K, Keir C. Global Manufacturing of CAR T Cell Therapy. Mol Ther Methods Clin Dev. 2017; 4:92-101. https://doi.org/10.1016/j. omtm.2016.12.006. [PubMed]

9. Goebeler ME, Bargou RC. T cell-engaging therapies BiTEs and beyond. Nat Rev Clin Oncol. 2020; 17:418-34. https://doi.org/10.1038/s41571-020-0347-5. [PubMed]

10. Zhu M, Wu B, Brandl C, Johnson J, Wolf A, Chow A, Doshi S. Blinatumomab, a Bispecific T-cell Engager (BiTE $\left({ }^{\circledR}\right)$ ) for CD-19 Targeted Cancer Immunotherapy: Clinical Pharmacology and Its Implications. Clin Pharmacokinet. 2016; 55:1271-88. https://doi.org/10.1007/s40262-0160405-4. [PubMed]

11. Topp MS, Gökbuget N, Stein AS, Zugmaier G, O'Brien S, Bargou RC, Dombret H, Fielding AK, Heffner L, Larson RA, Neumann S, Foà R, Litzow M, et al. Safety and activity of blinatumomab for adult patients with relapsed or refractory B-precursor acute lymphoblastic leukaemia: a multicentre, single-arm, phase 2 study. Lancet Oncol. 2015; 16:57-66. https://doi.org/10.1016/S1470-2045(14)71170-2. [PubMed]

12. Pishvaian M, Morse MA, McDevitt J, Norton JD, Ren S, Robbie GJ, Ryan PC, Soukharev S, Bao H, Denlinger CS. Phase 1 Dose Escalation Study of MEDI-565, a Bispecific T-Cell Engager that Targets Human Carcinoembryonic Antigen, in Patients With Advanced Gastrointestinal Adenocarcinomas. Clin Colorectal Cancer. 2016; 15:34551. https://doi.org/10.1016/j.clcc.2016.07.009. [PubMed]

13. Middelburg J, Kemper K, Engelberts $\mathrm{P}$, Labrijn AF, Schuurman J, van Hall T. Overcoming Challenges for CD3-Bispecific Antibody Therapy in Solid Tumors. Cancers (Basel). 2021; 13:287. https://doi.org/10.3390/ cancers 13020287. [PubMed]

14. Huston JS, Mudgett-Hunter M, Tai MS, McCartney J, Warren F, Haber E, Oppermann H. Protein engineering of single-chain Fv analogs and fusion proteins. Methods Enzymol. 1991; 203:46-88. https://doi.org/10.1016/00766879(91)03005-2. [PubMed]

15. Mallender WD, Voss EW Jr. Construction, expression, and activity of a bivalent bispecific single-chain antibody. J Biol Chem. 1994; 269:199-206. https://doi.org/10.1016/S00219258(17)42334-9. [PubMed]

16. Alhallak K, Sun J, Wasden K, Guenthner N, O'Neal J, Muz B, King J, Kohnen D, Vij R, Achilefu S, DiPersio JF, Azab AK. Nanoparticle T-cell engagers as a modular platform for cancer immunotherapy. Leukemia. 2021; 35:2346-57. https://doi.org/10.1038/s41375-021-011272. [PubMed]
17. Maakaron JE, Rogosheske J, Long M, Bachanova V, Mims AS. CD33-Targeted Therapies: Beating the Disease or Beaten to Death? J Clin Pharmacol. 2021; 61:7-17. https:// doi.org/10.1002/jcph.1730. [PubMed]

18. Ehninger A, Kramer M, Röllig C, Thiede C, Bornhäuser M, von Bonin M, Wermke M, Feldmann A, Bachmann M, Ehninger G, Oelschlägel U. Distribution and levels of cell surface expression of CD33 and CD123 in acute myeloid leukemia. Blood Cancer J. 2014; 4:e218. https://doi. org/10.1038/bcj.2014.39. [PubMed]

19. Walter RB, Appelbaum FR, Estey EH, Bernstein ID. Acute myeloid leukemia stem cells and CD33-targeted immunotherapy. Blood. 2012; 119:6198-208. https://doi. org/10.1182/blood-2011-11-325050. [PubMed]

20. Loke J, Khan JN, Wilson JS, Craddock C, Wheatley K. Mylotarg has potent anti-leukaemic effect: a systematic review and meta-analysis of anti-CD33 antibody treatment in acute myeloid leukaemia. Ann Hematol. 2015; 94:36173. https://doi.org/10.1007/s00277-014-2218-6. [PubMed]

21. Laszlo GS, Gudgeon CJ, Harrington KH, Dell'Aringa J, Newhall KJ, Means GD, Sinclair AM, Kischel R, Frankel $\mathrm{SR}$, Walter RB. Cellular determinants for preclinical activity of a novel CD33/CD3 bispecific T-cell engager (BiTE) antibody, AMG 330, against human AML. Blood. 2014; 123:554-61. https://doi.org/10.1182/ blood-2013-09-527044. [PubMed]

22. Ravandi F, Stein AS, Kantarjian HM, Walter RB, Paschka P, Jongen-Lavrencic M, Ossenkoppele GJ, Yang Z, Mehta B, Subklewe M. A Phase 1 First-in-Human Study of AMG 330, an Anti-CD33 Bispecific T-Cell Engager (BiTE ${ }^{\circledR}$ ) Antibody Construct, in Relapsed/Refractory Acute Myeloid Leukemia (R/R AML). Blood. 2018; 132:S25. https://doi.org/10.1182/ blood-2018-99-109762.

23. Ravandi F, Walter RB, Subklewe M, Buecklein V, JongenLavrencic M, Paschka P, Ossenkoppele GJ, Kantarjian HM, Hindoyan A, Agarwal SK, Dai T, Khaldoyanidi S, Stein AS. Updated results from phase I dose-escalation study of AMG 330, a bispecific T-cell engager molecule, in patients with relapsed/refractory acute myeloid leukemia (R/R AML). J Clin Oncol. 2020; 38:S7508. https://doi.org/10.1200/ JCO.2020.38.15 suppl.7508.

24. Westervelt P, Cortes JE, Altman JK, Long M, Oehler VG, Gojo I, Guenot J, Chun P, Roboz GJ. Phase 1 First-inHuman Trial of AMV564, a Bivalent Bispecific (2:2) CD33/ CD3 T-Cell Engager, in Patients with Relapsed/Refractory Acute Myeloid Leukemia (AML). Blood. 2019 (Suppl 1); 134:S834. https://doi.org/10.1182/blood-2019-129042.

25. Reusch U, Harrington KH, Gudgeon CJ, Fucek I, Ellwanger K, Weichel M, Knackmuss SH, Zhukovsky EA, Fox JA, Kunkel LA, Guenot J, Walter RB. Characterization of CD33/CD3 Tetravalent Bispecific Tandem Diabodies (TandAbs) for the Treatment of Acute Myeloid Leukemia. Clin Cancer Res. 2016; 22:5829-38. https://doi. org/10.1158/1078-0432.CCR-16-0350. [PubMed] 
26. O'Hear C, Heiber JF, Schubert I, Fey G, Geiger TL. AntiCD33 chimeric antigen receptor targeting of acute myeloid leukemia. Haematologica. 2015; 100:336-44. https://doi. org/10.3324/haematol.2014.112748. [PubMed]

27. Tambaro FP, Singh H, Jones E, Rytting M, Mahadeo KM, Thompson P, Daver N, DiNardo C, Kadia T, Garcia-Manero G, Chan T, Shah RR, Wierda WG. Autologous CD33CAR-T cells for treatment of relapsed/refractory acute myelogenous leukemia. Leukemia. 2021 Apr 8. https://doi. org/10.1038/s41375-021-01232-2. [Epub ahead of print]. [PubMed]

28. de la Puente P, Muz B, Gilson RC, Azab F, Luderer M, King J, Achilefu S, Vij R, Azab AK. 3D tissue-engineered bone marrow as a novel model to study pathophysiology and drug resistance in multiple myeloma. Biomaterials. 2015; 73:70 84. https://doi.org/10.1016/j.biomaterials.2015.09.017. [PubMed]

29. Alhallak K, de la Puente P, Jeske A, Sun J, Muz B, Rettig MP, Sahin I, Weisberg EL, Griffin JD, Reagan JL, DiPersio JF, Azab AK. 3D tissue engineered plasma cultures support leukemic proliferation and induces drug resistance. Leuk Lymphoma. 2021 May 17. https://doi.org/10.1080/104281 94.2021.1919657. [Epub ahead of print]. [PubMed]

30. Li J, Stagg NJ, Johnston J, Harris MJ, Menzies SA, DiCara D, Clark V, Hristopoulos M, Cook R, Slaga D, Nakamura R, McCarty L, Sukumaran S, et al. Membrane-Proximal Epitope Facilitates Efficient $\mathrm{T}$ Cell Synapse Formation by Anti-FcRH5/CD3 and Is a Requirement for Myeloma Cell Killing. Cancer Cell. 2017; 31:383-95. https://doi. org/10.1016/j.ccell.2017.02.001. [PubMed]

31. Luderer MJ, Muz B, Alhallak K, Sun J, Wasden K, Guenthner N, de la Puente P, Federico C, Azab AK. Thermal
Sensitive Liposomes Improve Delivery of Boronated Agents for Boron Neutron Capture Therapy. Pharm Res. 2019; 36:144. https://doi.org/10.1007/s11095-019-2670-Z. [PubMed]

32. Federico C, Alhallak K, Sun J, Duncan K, Azab F, Sudlow GP, de la Puente P, Muz B, Kapoor V, Zhang L, Yuan F, Markovic M, Kotsybar J, et al. Tumor microenvironmenttargeted nanoparticles loaded with bortezomib and ROCK inhibitor improve efficacy in multiple myeloma. Nat Commun. 2020; 11:6037. https://doi.org/10.1038/s41467020-19932-1. [PubMed]

33. de la Puente P, Luderer MJ, Federico C, Jin A, Gilson RC, Egbulefu C, Alhallak K, Shah S, Muz B, Sun J, King J, Kohnen D, Salama NN, et al. Enhancing proteasomeinhibitory activity and specificity of bortezomib by CD38 targeted nanoparticles in multiple myeloma. J Control Release. 2018; 270:158-76. https://doi.org/10.1016/j. jconrel.2017.11.045. [PubMed]

34. Sun J, Muz B, Alhallak K, Markovic M, Gurley S, Wang Z, Guenthner N, Wasden K, Fiala M, King J, Kohnen D, Salama NN, Vij R, Azab AK. Targeting CD47 as a Novel Immunotherapy for Multiple Myeloma. Cancers (Basel). 2020; 12:305. https://doi.org/10.3390/cancers12020305. [PubMed]

35. Muz B, Bandara N, Mpoy C, Sun J, Alhallak K, Azab F, Rogers BE, Azab AK. CXCR4-targeted PET imaging using $^{64} \mathrm{Cu}$-AMD3100 for detection of Waldenström Macroglobulinemia. Cancer Biol Ther. 2020; 21:52-60. https://doi.org/10.1080/15384047.2019.1665405. [PubMed] 